\title{
Solo un chiclet/Juste un chewing-gum
}

\section{Arnaud Mège}

\section{OpenEdition}

\section{Journals}

Édition électronique

URL : https://journals.openedition.org/itti/2053

DOI : 10.4000/itti.2053

\section{Éditeur}

Université de Poitiers

\section{Référence électronique}

Arnaud Mège, "Solo un chiclet/Juste un chewing-gum », Images du travail, travail des images [En ligne] 11 | 2021, mis en ligne le 01 septembre 2021, consulté le 18 février 2022. URL : http:// journals.openedition.org/itti/2053; DOI : https://doi.org/10.4000/itti.2053

Ce document a été généré automatiquement le 18 février 2022.

Images du travail, travail des images 


\section{Solo un chiclet/Juste un chewing-gum}

\section{Arnaud Mège}

Une vendeuse de chiclets à La Paz, Bolivie, 2014

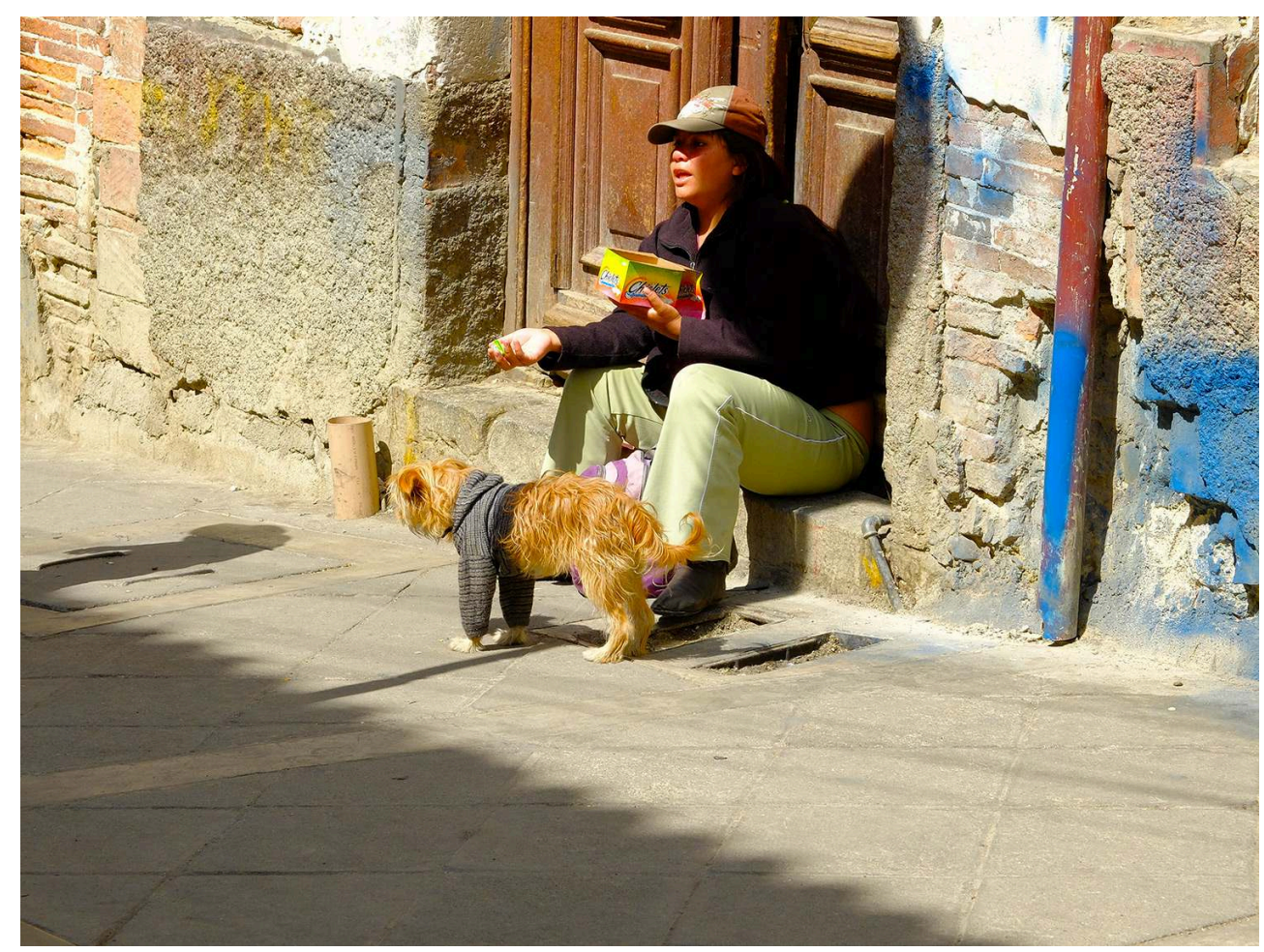

(C) Arnaud Mège

1 J'ai pris cette photo en 2014 durant un séjour itinérant de trois semaines et demi en Amérique du Sud. La scène se passe en Bolivie, dans une des rues de la ville de La Paz. Une jeune femme est assise sur la marche d'une entrée privative. Elle tient dans sa main droite quelque chose qu'elle propose à la vente aux passants. La boîte de chiclets (chewing-gum), bien visible dans sa main gauche, nous renseigne sur la nature du produit proposé : un chiclet, c'est-à-dire un chewing-gum à l'unité. 
2 Le sac qu'elle a pris le soin de poser entre ses pieds contient sûrement le reste de la marchandise et quelques bolivianos gagnés sur les ventes réalisées. Le chien qui se trouve devant elle est probablement le sien. Il porte un vêtement comme beaucoup d'autres que j'ai pu observer durant mon séjour. Cela ne semble donc pas participer d'un quelconque "folklore » visant à attirer le chaland mais à un usage relativement répandu.

3 La pratique du commerce ambulant est très courante en Bolivie, et plus largement en Amérique du Sud. Les gens s'organisent ainsi pour subvenir à leurs besoins dans une société qui permet encore de développer des pratiques commerciales peu contrôlées. On retrouve ainsi dans toutes les rues des centres urbains des stands, souvent tenus par des cholas, des femmes vêtues d'habits traditionnels reflets de la culture indigène, présentant des produits de consommation courante soigneusement mis en valeur sur des étoffes colorées.

Ici, la scène photographiée révèle une tout autre configuration. Cette jeune femme, coiffée d'une casquette et habillée selon les codes vestimentaires occidentaux, propose un produit unique, qui plus est au détail. Impossible d'acheter un paquet de chewinggum mais bien un chewing-gum pour une somme dont je ne peux me rappeler le montant aujourd'hui faute d'en avoir pris note sur le moment. Ainsi, la vente de chewing-gum au détail renvoie à des pratiques de commerce particulières, distantes des manières de consommer des pays occidentaux. Ce paquet qu'elle tient dans la main gauche, probablement acheté dans un petit commerce de la ville, représente à lui seul une opportunité de bénéfice économique probablement non négligeable pour cette jeune femme. Considérant cela, l'habit porté par le chien apparaît comme un paradoxe qui vient renforcer la charge symbolique de l'image. Alors que la jeune femme cherche à gagner quelques bolivianos, supposant ainsi qu'elle en manque, le vêtement porté par le chien apparaît comme un élément esthétique superflu, renvoyant à des représentations culturellement situées définissant cet objet comme un élément de distinction affiché.

\section{AUTEUR}

\section{ARNAUD MÈGE}

Arnaud Mège est sociologue et urbaniste. Il est actuellement postdoctorant au sein du laboratoire HABITER de l'Université de Reims Champagne-Ardenne et enseignant vacataire à l'IATEUR (Institut d'Aménagement des Territoires, d'Environnement et d'Urbanisme de Reims). Il a mené des recherches sur les formes d'engagement en faveur de l'écologie radicale et la décroissance. Actuellement, ses travaux interrogent notamment la variabilité des rapports au temps qu'entretiennent les acteurs qui contribuent à mener des projets en faveur d'un urbanisme durable.

Page personnelle : https://www.univ-reims.fr/media-files/24579/mege_fiche-chercheur.pdf 